\title{
Granulomatous gastritis in Wegener's disease: differentiation from Crohn's disease supported by a positive test for antineutrophil antibodies
}

\author{
B Temmesfeld-Wollbrueck, C Heinrichs, A Szalay, W Seeger
}

\begin{abstract}
Background-This report concerns the gastric manifestation of Wegener's granulomatosis in a 44 year old white female patient who initially presented with abdominal pain, vomiting, and iridocyclitis.

Findings-The clinical findings and the histopathological proof of granulomatous gastritis in the absence of necrotising vasculitis were initially considered to be indicative of a diagnosis of Crohn's disease showing isolated gastric involvement. A five month course of steroids resulted in temporary relief; thereafter the patient developed severe rhinitis with mucosal ulcerations. At this point biopsy of nasal mucosa disclosed the classic histopathological signs of Wegener's granulomatosis. A positive test for antineutrophil cytoplasmic antibodies (ANCAs) with a cytoplasmic pattern (c-ANCA) and antigenic specificity for proteinase 3 (PR-3) were found. The patient is in complete remission one year after diagnosis and treatment with steroids and cyclophosphamide.

Conclusions-Wegener's granulomatosis can also involve the gastrointestinal tract. Granulomatous inflammation of the stomach, although a rare finding and nonspecific, should include Wegener's disease in the differential diagnosis. The histological proof of necrotising vasculitis is dependent on the depth of the biopsy and therefore can be easily missed. Differential diagnosis can be clarified by ANCA testing.
\end{abstract}

(Gut 1997; 40: 550-553)

Keywords: Wegener's granulomatosis, granulomatous gastritis.

Wegener's granulomatosis is a systemic vasculitis, in most cases involving the respiratory tract and the kidneys although almost any organ can be affected. Typical histopathological features are a polymorphous vasculitis often associated with parenchymal necrosis and granulomatous inflammation. In addition to the clinical picture and the typically occurring histopathological alterations, serological proof of antineutrophil cytoplasmic antibodies (ANCAs) plays an important part in diagnosing the disease. Two distinct patterns of ANCAs are distinguished by indirect immunofluorescence staining of alcohol fixed neutrophils: cytoplasmic granular (c-ANCA) and perinuclear granular (p-ANCA). Proteinase 3 (PR-3), contained in azurophil granules, has been identified as the target antigen of c-ANCA in patients with vasculitis. The c-ANCA fluorescence pattern has a specificity for Wegener's granulomatosis that is close to $100 \%$ and the titre correlates well with disease activity. Myeloperoxidase (MPO) is the usual antigen to which p-ANCA are reactive in patients with vasculitis. However, a subset of p-ANCA, which generally does not react with MPO, has been found in most patients with ulcerative colitis (specificity $94 \%$, sensitivity $60 \%$ ) and sclerosing cholangitis without correlation with disease activity.

Gastrointestinal manifestation in Wegener's granulomatosis has rarely been reported. An intestinal Wegener's granulomatosis may present with abdominal pain, blood stained mucus diarrhoea, and intestinal perforation and may therefore mimic inflammatory or infective bowel disease. ${ }^{1-8}$ Predominant involvement of the stomach has hitherto not been reported. The presented case of gastric involvement shows the necessity to consider Wegener's granulomatosis in illnesses with histological evidence of granulomatous inflammation even when a vasculitis is histologically not apparent and when clinical signs do not correspond with those of a classic Wegener's granulomatosis.

\section{Case report}

A 44 year old white woman presented with conjunctival reddening, abdominal pain, vomiting, and weight loss of two weeks duration. The patient had a two year history of unclarified raised erythrocyte sedimentation rate and anaemia. She was admitted to a local hospital where laboratory studies disclosed the following values: erythrocyte sedimentation rate $67 \mathrm{~mm} / \mathrm{h}$, white blood cell count $16.3 / \mathrm{nl}$ ( $84 \%$ polymorphnuclear leucocytes, $1 \%$ band forms, $9 \%$ lymphocytes, and $6 \%$ monocytes); haemoglobin $8.7 \mathrm{~g} / \mathrm{dl}$; packed cell volume $29 \%$; thrombocytes $821 / \mathrm{nl}$; total serum protein $63 \mathrm{~g} / 1$ with $38.3 \%$ albumin, $9 \cdot 4 \%$ 
$\alpha 1$-globulin, $17 \cdot 8 \% \quad \alpha 2$-globulin, $12 \cdot 7 \% \quad \beta$ globulin, and $21.8 \% \gamma$-globulin; test for occult blood in stools was positive; antinuclear factor negative. A gastroscopy was performed and in the region of the fundus, antrum, and bulbus partly polypoid and partly erosive mucosal alterations were found. Biopsy showed a sarcoid-like chronic granulomatous inflammation with mucosal ulceration including Langerhans' and foreign body type giant cells and non-specific findings such as pseudopolypoid foveolar hyperplasia (Fig 1). Necrotising vasculitis could not be detected. Synopsis of histopathology and clinical presentation suggested a diagnosis of Crohn's disease as the most probable. Further investigations included normal chest and sinus radiographs. Urinary analysis showed microscopic haematuria but no proteinuria; creatinine clearance was $79 \mathrm{ml} / \mathrm{min} \mathrm{m}^{2}$. An ophthalmic examination showed a bilateral iridocyclitis. A colonoscopic examination performed 10 to $15 \mathrm{~cm}$ into the terminal ileum and a small bowel follow through study gave normal results, as did the microscopic examination of biopsy specimens from the large and the small bowel. No lymphadenopathy or other abnormalities were seen on computed tomography (CT). Treatment with $20 \mathrm{mg}$ prednisolone was started. After three weeks the gastric mucosal changes showed regression and the ophthalmic inflammation was healed. The steroid medication was gradually reduced over a period of five months. Four weeks after cessation of prednisolone treatment, painful rhinitis with nasal blockage and epistaxis developed. There was crusting granulation and ulceration and a biopsy of the nasal mucosa was performed. Histopathological examination showed a granulomatous inflammation and an obliterative arteritis characteristic of Wegener's granulomatosis. The granuloma showed accumulations of epitheloid cells and giant cells, mostly of foreign body type. The vessels showed transmural lymphoid infiltration associated with proliferation of the intima and fragmentation of the elastic lamina associated with tissue necrosis (Fig 2). The patient was admitted to hospital. On admission the nasal mucosa was oedematous with secretion of bloody mucus. The patient reported a constant feeling of epigastric pressure over the past few months. She was able to take only small portioned meals and reported no vomiting. She complained of fatigue and lethargy together with a strong feeling of malaise. The patient showed no signs of arthralgia or arthritis. An ophthalmic examination now disclosed no abnormalities. Urinary analysis and chest and sinus radiography were normal. Results of laboratory investigations were similar to those mentioned earlier.

At this point an examination for ANCAs showed a positive c-ANCA (titre $1: 64$ ) by way of immunofluorescence and positive enzyme linked immunosorbent assay (ELISA) test for proteinase $3 \quad(47.3 \mathrm{U} / \mathrm{ml}$ (normal <7)). Gastroscopy showed multiple small polypoid changes with a diameter between 0.5 and $1 \mathrm{~cm}$ in the fundus, antrum, and pylorus. There was no macroscopic florid inflammation but a mild,
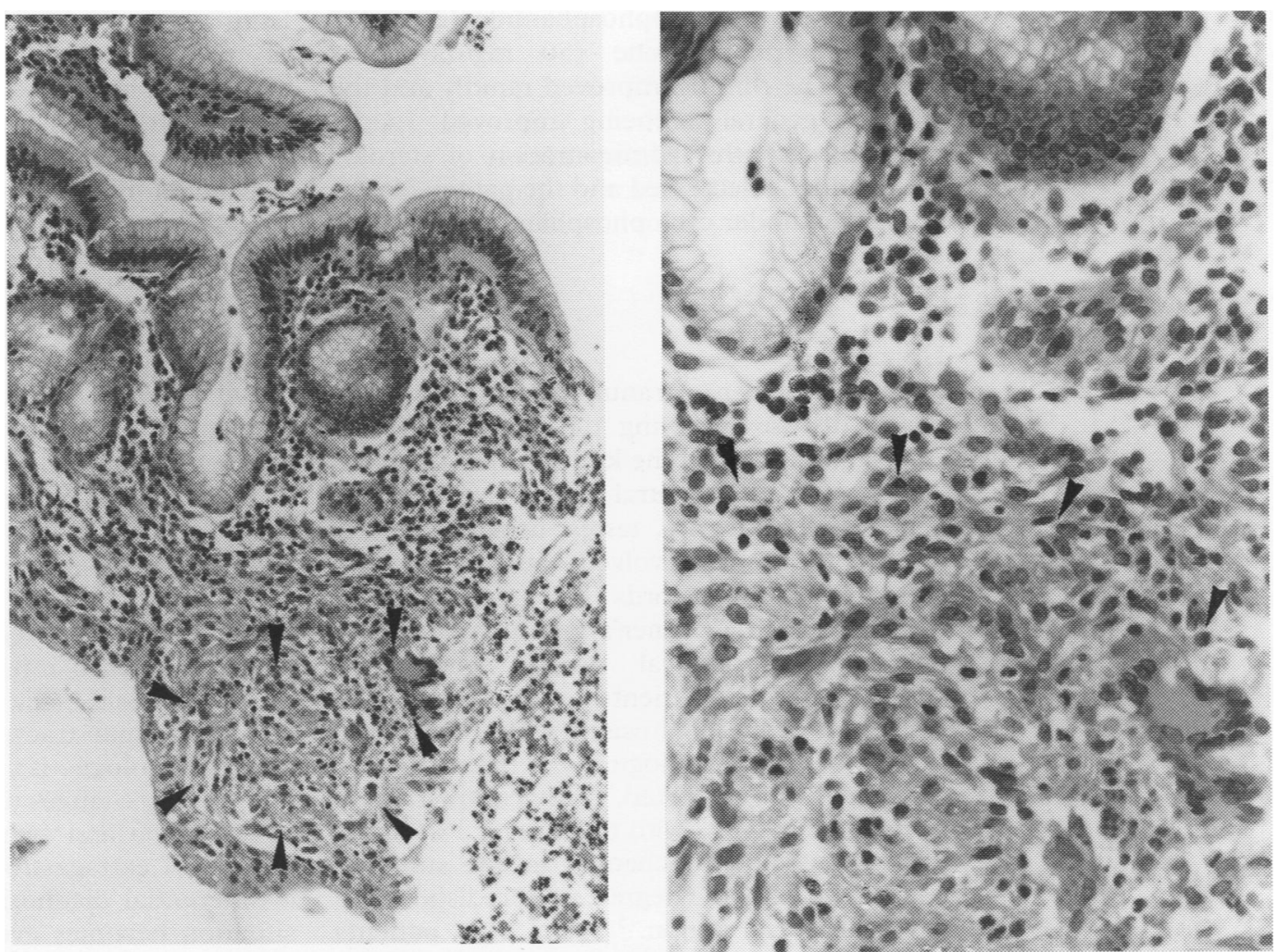

Figure 1: (A) Gastric biopsy specimen before treatment: sarcoid-like granuloma (arrows) in the lamina propria including Langerhans' giant cells. Superficial gastric foveolae. Findings indicative of granulomatous gastritis (haematoxylin and eosin, originally $\times 250$ ). (B) Higher magnification (haematoxylin and eosin, originally $\times 750$ ). 


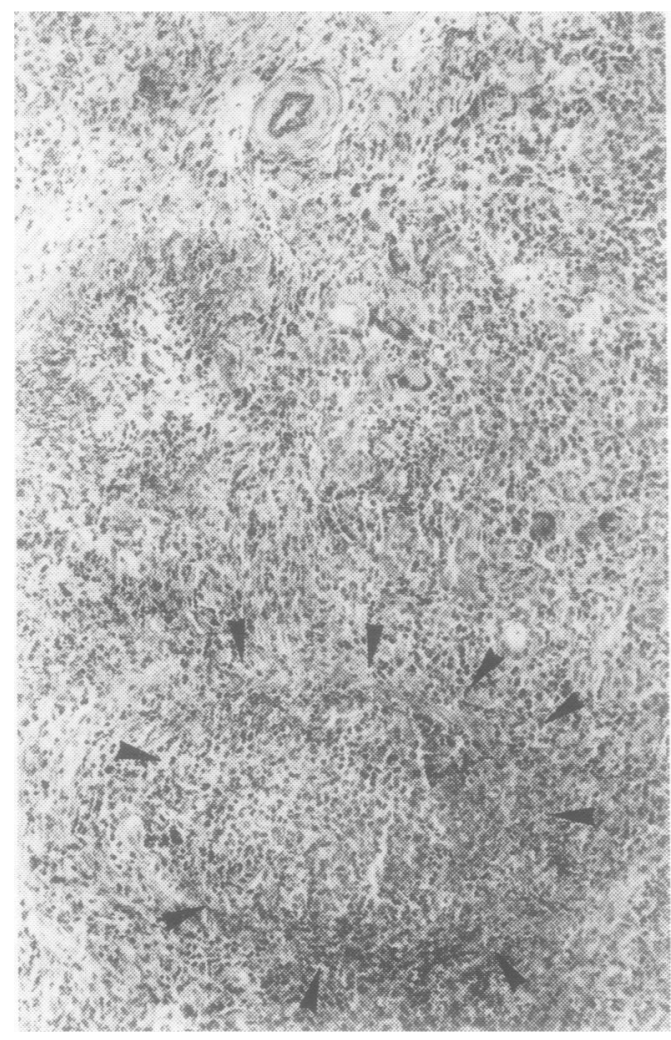

Figure 2: Biopsy sample of nasal mucosa. Vasculitis with transmural lymphoid infiltration and fragmentation of elastic tissue (arrows). Superficial necrosis. Focally giant cells. Findings diagnostic of Wegener's disease (Goldnerelastica originally $\times 50$.

non-specific fibrosing chronic inflammation was detected histologically. Colonoscopy, small bowel follow through study, and CT of the abdomen again showed no abnormalities. Treatment with cyclophosphamide $(2 \mathrm{mg} / \mathrm{kg} /$ day) and prednisolone (50 mg/day) was started. The rhinitis improved rapidly and the patient's general wellbeing improved. In the next four months, administration of steroids was gradually decreased and the patient is now doing well under cyclophosphamide treatment alone.

\section{Discussion}

Classic Wegener's granulomatosis is a vasculitic disease involving the upper or lower respiratory tract and the kidneys in most cases. The peripheral or central nervous system, eye, heart, spleen, ovaries, testes, ureter, prostate, and skin can be involved, but this is less common. Case records on gastrointestinal involvement in Wegener's granulomatosis are rare. In six clinical reviews comprising altogether 326 patients with established Wegener's granulomatosis, no gastrointestinal symptoms or histologically confirmed involvement were reported. ${ }^{9-14}$ By contrast, in 39 necropsied patients with the disease $13(33 \%)$ showed histological changes in the small or large bowel to some degree, not predisposed to any particular region. ${ }^{15-17}$ In two patients vasculitis was found in the stomach. ${ }^{17} \mathrm{Ob}$ viously, clinically undetected changes in the gastrointestinal tract are not unusual at least in lethal forms of Wegener's granulomatosis. In published reports (eight case records) clinical presentation includes intestinal infarction, ${ }^{4}$ small bowel perforation, ${ }^{2} 67$ large bowel perforation, ${ }^{7}$ intestinal haemorrhage, ${ }^{58}$ and blood stained mucus diarrhoea. ${ }^{13}$ Although tissue samples from macroscopically inflamed areas were available in six cases a vasculitis was identified histologically in only three cases. A clear correlation between gastrointestinal involvement and Wegener's granulomatosis, however, existed in all cases.

Initially, our patient was diagnosed as having Crohn's disease with an unusual isolated gastric involvement. This was in part based on the histological finding of a granulomatous gastritis. Sarcoid-like epitheloid granulomas including epitheloid cells and giant Langerhans' cells with occasional giant cells of foreign body type were seen in the superficial lamina propria of the antral gastric mucosa (Fig 1). This finding was accompanied by florid ulceration including fibrin and segmented granulocytes. Further granulation tissue with early fibrosis and lymphofollicular infiltration were noted. Residual gastric mucosa focally showed pronounced foveolar hyperplasia with variably sized antral glands indicating regenerative epithelial changes. There was no indication of less probable causes of granulomatous diseases such as lymphomatous infiltrate (Hodgkin's disease) or infective agents (fungus, acid fast bacilli, Yersinia species). Infectious causes were ruled out by special stains, serological tests, and clinical findings. A diagnosis of Wegener's disease was not considered at this point as no vasculitis was seen. No pathological involvement of arterial vessels was detectable (elastic stain) within the lamina propria. Arteries in normal mucosa are of small size and difficult to detect. The major vascular plexus, including medium sized arteries and veins that are usually altered in Wegener's disease, is present in the submucosa and therefore not easily accessible to biopsy. The histological criterion of vasculitis cannot always be seen in nasal mucosa. Thus taking into account the more superficial localisation of the nasal arteries, a positive proof of vasculitis in the stomach can be expected to be even more difficult. Extraintestinal involvement - for example, iridocyclitis - also seemed to fit the diagnosis of Crohn's disease at this time. Differential diagnosis is often difficult as Crohn's disease shares many features with Wegener's granulomatosis. Sokol et al also reported an unusual intestinal involvement in Wegener's granulomatosis, which mimicked inflammatory bowel disease in a 16 year old black woman. ${ }^{3}$ Apart from the gastrointestinal tract, overlapping of clinical symptomatology is also expressed in inflammatory changes of the eye and skin as well as arthralgia and arthritis. Depending on the pattern of extragastrointestinal manifestations a differential diagnosis may be difficult. The situation becomes even more complicated as granulomatous vasculitis has been reported as a possible feature of Crohn's disease in reaction to a persistent measles virus infection within 
the vascular endothelium. ${ }^{18-20}$ In such a case testing for ANCA can be a decisive diagnostic tool. As already outlined, there is a strong correlation between c-ANCA and active Wegener's granulomatosis with a major antigen specificity for proteinase-3..$^{21} 22$ In Crohn's disease c-ANCAs are not found. However, 2\% to $25 \%$ of cases are positive for p-ANCA with non-homogeneous antigen specificity. ${ }^{23} 2425$ Therefore, the positive testing for c-ANCA with antigen specificity for proteinase 3 made the diagnosis of Crohn's disease extremely unlikely. Unfortunately, ANCA testing was initially not considered and was performed after a delay. Therefore, it remains unclear whether the differential diagnosis could have been clarified in the early stages of disease.

The diagnosis of Wegener's granulomatosis was established on the basis of the clinical findings and a positive test for c-ANCA together with the histological proof of a granulomatous inflammation and obliterative arteritis with subsequent ulceration in a biopsy sample of the nasal mucosa (Fig 2). At this point a control biopsy sample of gastric mucosa disclosed a non-specific chronic fibrosing inflammation as seen in any healing mucosal erosion probably due to the prior steroid therapy.

To our knowledge this is the first description of a granulomatous gastritis in Wegener's granulomatosis. Although uncommon, intestinal involvement may be a major feature in Wegener's granulomatosis. Diagnosis should be considered in patients presenting with bowel symptoms accompanied by evidence of systemic vasculitis or with histological proof of granulomatous inflammation. In patients with suspected Crohn's disease the differential diagnosis of Wegener's granulomatosis must be considered and ANCA testing should be used as a diagnostic measure to clarify differential diagnosis.

Histological material was provided in part by $\mathrm{D}$ Kunde, Institute of Pathology, Siegen, Germany.

1 Haworth SJ, Pusey CD. Severe intestinal involvement in Wegener's granulomatosis. Gut 1984; 25: 1296-300.

2 Tokuda M, Kurata N, Daikuhara H, Akisawa M, Onishi I Asano T, et al. Small intestinal perforation in Wegener's granulomatosis. F Rheumatol 1989; 16: 547-9.

3 Sokol RJ, Farrell MK, McAdams AJ. An unusual presentation of Wegener's granulomatosis mimicking inflammatory bowel disease. Gastroenterology 1984; 87: 426-32.
4 Tupler RH, McCuskey WH. Wegener granulomatosis of the colon: CT and histologic correlation. $\mathcal{f}$ Comput Assist Tomogr 1991; 15: 314-6.

5 Pinkney JH, Clarke G, Fairclough PD. Gastrointestinal involvement in Wegener's granulomatosis. Gastrointest Endosc 1991; 37: 411-2.

6 McNabb WR, Lennox MS, Wedzicha JA. Small intestinal perforation in Wegener's granulomatosis. Postgrad Med 7 1982; 58: 123-5.

7 Geraghty J, Mackay IR, Smith DC. Intestinal perforation in Wegener's granulomatosis. Gut 1986; 27: 450-1.

8 Coward RA, Gibbons CP, Brown CB, Raftery AT, Parsons MA, Shortland JR. Gastrointestinal haemorrhage complicating Wegener's granulomatosis. BMF 1985; 291: 865-6.

9 Fauci AS, Haynes BF, Katz P, Wolff SM. Wegener's granulomatosis: prospective clinical and therapeutic experience with 85 patients for 21 years. Ann Intern Med 1983; 98: 76-85.

10 Hoffman GS, Kerr GS, Leavitt RY, Hallahan CW, Lebovics RS, Travis WD, et al. Wegener granulomatosis: an analysis of 158 patients. Ann Intern Med 1992; 116: 488-98.

11 Brandwein S, Esdaile J, Danoff D, Tannenbaum H. Wegener's granulomatosis. Clinical features and outcome in 13 patients. Arch Intern Med 1983; 143: 476-9.

12 Pinching AJ, Lockwood CM, Pussell BA, Rees AJ, Sweny P, Evans DJ, et al. Wegener's granulomatosis: observations on 18 patients with severe renal disease. $Q$ f Med 1983; 208: 435-60.

13 Littlejohn GO, Ryan PJ, Holdsworth SR. Wegener's granulomatosis: clinical features and outcome in seventeen patients. Aust NZ f Med 1985; 15: 241-5.

14 Romas E, Kennedy JT, Murphy BF, Niall JF, d'Apice AJF. Wegener's granulomatosis: clinical features and prognosis in 37 patients. Aust NZ $¥$ Med 1993; 23: 168-75.

15 Fauci AS, Wolff SM. Wegener's granulomatosis: studies in 18 patients and a review of the literature. Medicine 1973;

16 Carrington CB, Liebow AA. Limited forms of angiitis and granulomatosis of Wegener's type. Am f Med 1966; 41: 497-527.

17 Godman GC, Churg J. Wegener's granulomatosis. Arch Pathol 1954; 58: 533-53.

8 Wakefield AJ, Sawyerr AM, Dhillon AP, Pittilo RM, Rowles PM, Lewis AAM. Pathogenesis of Crohn's disease: multifocal gastrointestinal infarction. Lancet 1989; ii: 1057-62.

19 Wakefield AJ, Sankey EA, Dhillon AP, Sawyerr AM, More $\mathrm{L}$, Sim R, et al. Granulomatous vasculitis in Crohn's disease. Gastroenterology 1991; 100: 1279-87.

20 Wakefield AJ, Ekbom A, Dhillon AP, Pittilo RM, Pounder RE. Crohn's disease: pathogenesis and persistent measles virus infection. Gastroenterology 1995; 108: 911-6.

21 van der Woude FJ, Rasmussen N, Lobatto S, Wiik A, Permin H, Van Es LA, et al. Autoantibodies against neutrophils and monocytes: tool for diagnosis and marker of disease in Wegener's granulomatosis. Lancet 1985; i:425-9.

22 Goldschmeding $R$, Van Der Schoot CE, Ten Bokkel Huinink D, Hack CE, Van Den Ende ME, Kallenberg CG, Von Dem Borne AE. Wegener's granulomatosis autoantibodies identify a novel diisopropylfluorophosphate-b normal human neutrophils. F Clin Invest 1989; 84: normal hum

23 Rump JA, Roth $M$, Scholmerich J, Helfesrieder $R$, Ludemann J, Gross WL, et al. A new type of ANCA in sera of patients with ulcerative colitis: effects of therapy and disease severity on serum titer. Immun Infekt 1992; 20: 16-8.

24 Seibold F, Weber P, Klein R, Berg PA, Wiedmann KH. Clinical significance of antibodies against neutrophils in patients with inflammatory bowel disease and primary sclerosing cholangitis. Gut 1992; 33: 657-62.

25 Seibold F, Slametschka D, Gregor M, Weber P. Neutrophil autoantibodies: a genetic marker in primary sclerosing cholangitis and ulcerative colitis. Gastroenterology 1994; 107: 532-6. 